\title{
Corticosteroid-induced sinus bradycardia in a young boy with adrenal insufficiency and sepsis
}

\author{
Emine A. Cimbek M.D. ${ }^{a}$, Gülay Kaya M.D. ${ }^{b}$, Mehmet A. Öztürk M.D. ${ }^{c}$, Embiya Dilber Prof. ${ }^{d}$ and \\ Gülay Karagüzel Prof.
}

\begin{abstract}
The literature does not commonly describe cardiac rhythm disturbances, including bradycardia, in patients who are receiving corticosteroids, and the exact mechanism of such disturbances remains unknown. Herein, we present a case of sinus bradycardia associated with stress-dose corticosteroid therapy. A nine-year-old boy with a history of panhypopituitarism was admitted with gastroenteritis and pneumonia and developed septic shock on the day of admission. Management using intravenous fluids, stress doses of hydrocortisone, and antibiotics resulted in full recovery. However, within 24 hours following treatment, sinus bradycardia was documented, with a heart rate of 45 beats per minute (BPM). The bradycardia resolved after the dose of hydrocortisone was decreased gradually. Corticosteroidinduced sinus bradycardia is an adverse effect that usually resolves after corticosteroid treatment is discontinued. During stress-dose corticosteroid therapy, hemodynamic monitoring should be considered. To our knowledge, this is the first report of sinus bradycardia following the use of hydrocortisone in children who have adrenal insufficiency.

Key words: corticosteroid, bradycardia, adrenal insufficiency.
\end{abstract}

http: / / dx.doi.org/10.5546/ aap.2021.eng.e353

To cite: Cimbek EA, Kaya G, Öztürk MA, Dilber E , Karagüzel G. Corticosteroid-induced sinus bradycardia in a young boy with adrenal insufficiency and sepsis. Arch Argent Pediatr 2021;119(4):e353-e356.

a. Karadeniz Technical University, Faculty of Medicine, Department of Pediatric Endocrinology, Trabzon, Turkey.

b. Karadeniz Technical University, Faculty of Medicine, Division of Pediatrics, Trabzon, Turkey.

c. İstanbul University Cerrahpaşa, Faculty of Medicine, Division of Pharmacology, İstanbul, Turkey.

d. Karadeniz Technical University, Faculty of Medicine, Department of Pediatric Cardiology, Trabzon, Turkey.

e. Karadeniz Technical University, Faculty of Medicine, Department of Pediatric Endocrinology, Trabzon, Turkey.

E-mail address:

Emine A. Cimbek, M.D.: eminay89@yahoo.com

Funding: None.

Conflict of interest: None.

Received: 9-15-2020

Accepted: 3-1-2021

\section{INTRODUCTION}

Corticosteroids are the standard treatment for adrenal insufficiency (AI). For primary AI, the maintenance dose of hydrocortisone is from $8-15 \mathrm{mg} / \mathrm{m}^{2} /$ day, while patients with secondary AI may be maintained on a lower dose. In patients with AI, stress dosing of hydrocortisone (50$100 \mathrm{mg} / \mathrm{m}^{2} /$ dose) is recommended in situations of physical stressors such as critical illness and surgery to prevent and treat adrenal crisis. ${ }^{1}$ High-dose, or "pulse," corticosteroid therapy (PST) is an important therapeutic strategy used in many disorders, including musculoskeletal, dermatological, neurological, nephrological, and neoplastic diseases. ${ }^{2}$

Corticosteroids have various adverse effects, including hyperglycemia, hypertension, weight gain, hyperlipidemia, increased risk of infections, osteoporosis, and depression. Cardiac rhythm disturbances, including both tachyarrhythmia and bradyarrhythmia, are known to a lesser extent. The literature has implicated prednisone, prednisolone, methylprednisolone, and dexamethasone as causative agents of bradycardia, but hydrocortisone has been identified only several times..$^{2-4}$ The intimate mechanism of bradycardia has not been elucidated, nor has its relationship to the dose or route of administration. ${ }^{3,4}$

Corticosteroid-induced bradycardia has not been previously reported in children with AI. Herein, we describe a young boy with AI who developed sinus bradycardia following stress dosing with hydrocortisone to manage sepsis in a critical setting.

\section{Case}

A nine-year-old boy with a history of panhypopituitarism secondary to pituitary hypoplasia presented to the emergency department with a one-day history of fever, vomiting, and diarrhea. Five days prior, the patient had presented with coughing, at which time a five-day course of clarithromycin had been prescribed. However, the patient could not tolerate that treatment and appeared confused 
and sleepy while at home, prompting his family to present to the hospital. The patient's medical history was significant for hypothyroidism, adrenal insufficiency, and growth hormone deficiency, all well controlled. For four years, the patient had been taking levothyroxine $(2.5 \mu \mathrm{g} /$ $\mathrm{kg})$ once daily, hydrocortisone $\left(12 \mathrm{mg} / \mathrm{m}^{2} /\right.$ day), and growth-hormone therapy $(0.033 \mathrm{mg} / \mathrm{kg})$ at bedtime. The patient had no cardiovascular disease. Blood pressure was $95 / 50 \mathrm{mmHg}$, heart rate 115 beats per minute (BPM), temperature $38{ }^{\circ} \mathrm{C}$, and oxygen saturation $99 \%$ on room air. Height and weight were $110 \mathrm{~cm}$ (25th percentile) and $23 \mathrm{~kg}$ (50th percentile), respectively. The patient was moderately dehydrated and lethargic, with coarse rales over the lungs and increased bowel sounds. The workup studies (Table 1) revealed elevated levels of C-reactive protein and procalcitonin. A chest radiograph showed pulmonary infiltrates. Initially, the patient received an isotonic sodium chloride bolus and $50 \mathrm{mg} / \mathrm{m}^{2}$ of hydrocortisone (sodium succinate) as an intravenous bolus. Thirty minutes after admission, respiratory arrest with hypotension (blood pressure of $65 / 40 \mathrm{mmHg}$ ) and hypoglycemia $(30 \mathrm{mg} / \mathrm{dl})$ were detected. Considering the diagnosis of acute AI (adrenal crisis) and septic shock, a second hydrocortisone bolus and isotonic sodium chloride bolus were administered, as was parenteral glucose supplementation. Mechanical ventilatory support was decided on. Midazolam and fentanyl were administered for sedation. Due to the patient's lack of response to hydrocortisone as part of treatment for refractory shock, the hydrocortisone dose was increased to $300 \mathrm{mg} / \mathrm{m}^{2} / \mathrm{day}$,

TABLE 1. Laboratory data of patient at admission

\begin{tabular}{lcc}
\hline Patient value & \multicolumn{2}{c}{ Reference range } \\
\hline Glucose $(\mathrm{mg} / \mathrm{dL}-\mathrm{mmol} / \mathrm{L})$ & $85-4.7$ & $74-106$ \\
Sodium $(\mathrm{mmol} / \mathrm{L})$ & 131 & $136-146$ \\
Potassium $(\mathrm{mmol} / \mathrm{L})$ & 4 & $3.5-5.1$ \\
Creatinine $(\mathrm{mg} / \mathrm{dL})$ & 0.73 & $0.67-1.17$ \\
Blood urea nitrogen $(\mathrm{mg} / \mathrm{dL})$ & 21 & $6-20$ \\
Hemoglobin $(\mathrm{g} / \mathrm{dL})$ & 11.3 & $11-15$ \\
Leukocyte $\left(\times 10^{3} / \mathrm{microL}\right)$ & 15.2 & $4.8-10.8$ \\
Platelet $\left(\times 10^{3} / \mathrm{microL}\right)$ & 225 & $130-400$ \\
C-reactive $\mathrm{protein}(\mathrm{mg} / \mathrm{L})$ & 141 & $<5$ \\
Procalcitonin $(\mathrm{mg} / \mathrm{L})$ & 5.31 & $<0.5$ \\
Arterial $\mathrm{pH}$ & 7.35 & $7.35-7.45$ \\
\multicolumn{1}{c}{$\mathrm{HCO}_{3}(\mathrm{mmol} / \mathrm{L})$} & 18.4 & $22-26$ \\
$\mathrm{PCO}_{2}(\mathrm{mmHg})$ & 31.3 & $32-48$ \\
\hline
\end{tabular}

administered as a continuous intravenous infusion. Dopamine administration was begun, and the patient was transferred to the intensive care unit. Ceftriaxone and metronidazole were begun. The patient's blood pressure improved on stress doses of corticosteroid and hydration; however, within 24 hours following treatment, he developed bradycardia (a heart rate in the waking state below the normal range for age, which was a rate of $70 \mathrm{BPM}$ in this case), with a heart rate of $45 \mathrm{BPM}$. An electrocardiogram confirmed a diagnosis of sinus bradycardia. Transthoracic echocardiogram was normal. Levothyroxine and growth-hormone therapies were initiated as soon as the patient's hemodynamic status was stabilized, and vancomycin was added to the therapy on day 2 .

The patient remained intubated until day 3, after which he made remarkable recovery. Dopamine was discontinued. Despite discontinuation on day 3 of midazolam and fentanyl, which are known to have negative chronotropic effects, the patient's heart rate ranged between 35 and $75 \mathrm{BPM}$. Although he was asymptomatic, atropine was administered once, on day 6 , when the patient's lowest heart rate was recorded as $35 \mathrm{BPM}$ while receiving $100 \mathrm{mg} /$ $\mathrm{m}^{2} /$ day of hydrocortisone. After this atropine administration, the patient's heart rate fluctuated between 50 and 75 BPM. Hydrocortisone infusion was gradually tapered to $25 \mathrm{mg} / \mathrm{m}^{2} /$ day, and the patient was transitioned to oral hydrocortisone on day 10 . The bradycardia finally resolved after the dose was tapered to $12 \mathrm{mg} / \mathrm{m}^{2} /$ day on day 15 . When the medications were examined for negative chronotropy, hydrocortisone and vancomycin were identified as having the potential for bradycardia. Because vancomycin was begun after the documentation of bradycardia, it was concluded that the patient had experienced hydrocortisone-induced bradycardia. For the remainder of the patient's hospital stay, his heart rate remained within normal limits, and he was discharged on day 17. The patient has since (for one year) remained in good health, with no problems detected on follow-ups at the endocrinology and cardiology units.

\section{DISCUSSION}

Corticosteroids may cause different types of arrhythmias. The most serious effect observed was sudden death, although the presence of significant coexisting diseases in that case makes it difficult to attribute causality. ${ }^{2}$ Vasheghani- 
Farahani et al., performed cardiac monitoring in patients with multiple sclerosis who were receiving high doses of methylprednisolone (1000 mg) intravenously. The most common arrhythmia observed was sinus tachycardia, which occurred in $83.8 \%$ of patients. Sinus bradycardia was detected in $41.9 \%$ of the rhythms recorded. The other types of cardiac arrhythmias detected included sinus arrest, sinus exit block, atrial fibrillation, and ventricular tachycardia ${ }^{5}$. Lucas et al., published the case of a two-yearold girl treated for a primitive neuroectodermal tumor who developed shock after ondansetron and high-dose methylprednisolone were administered. They concluded that this was an idiosyncratic reaction to the rapid administration of PST. ${ }^{6}$

Although the literature describes the association between bradycardia and corticosteroids, it is rarely symptomatic and perhaps little detected. Most reports describing adverse cardiovascular events involved highdose corticosteroids administered intravenously. Miura et al., reported sinus bradycardia in $82 \%$ of children with Kawasaki disease who received intravenous methylprednisolone therapy $(30 \mathrm{mg} /$ $\mathrm{kg}$ / day) for three days. ${ }^{7}$ However, cases have also emerged during infusion of low doses and using the oral route. Nagakura et al., showed that a dose of $2 \mathrm{mg} / \mathrm{kg} /$ day of methylprednisolone was related to bradycardia in children with Kawasaki disease. ${ }^{8}$ Üsküdar et al., noted a patient who developed sinus bradycardia during treatment with $52 \mathrm{mg}$ of oral methylprednisolone and who was shifted to prednisolone but developed bradycardia again and recovered only after dose reduction. ${ }^{3}$

Several hypotheses have been suggested to explain the mechanism of corticosteroid-induced rhythm disturbances. One potential explanation is baroreceptor-mediated reflex bradycardia in response to hypertension, but that is not applicable in our patient, whose blood pressure was normal during the entire bradycardic period. ${ }^{4}$ Another potential mechanism may be blunting of the chronotropic response to catecholamines due to alterations in myocardial beta-adrenergic receptor sensitivity and direct action on the myocardial membrane. ${ }^{9}$ It has been proposed that abnormal cardiac rhythms may be a consequence of transient direct damage to the myocardium. ${ }^{4}$ Because our patient's echocardiography was normal, this explanation is less likely in this case. Transient shifts of electrolytes, especially potassium and calcium, across the myocardial cell membrane may also play an important role. ${ }^{4}$ Although our patient's serum electrolyte levels were normal, we support electrolyte monitoring during corticosteroid treatment in patients who have underlying diseases. Furthermore, cardiac monitoring and slow rates of infusion should be considered. ${ }^{10}$

The Naranjo scale is a tool used to assess the probability of an adverse drug event and determine causality, and it has scores between 0 and 13. In our case, given the suspicion of an adverse drug reaction to hydrocortisone, we calculated the score as 8 , which indicates a probable causality. ${ }^{11}$

Most cases of corticosteroid-induced sinus bradycardia described in the literature were well tolerated, asymptomatic, and included spontaneous recovery over a variable period after treatment was discontinued or the dose reduced. ${ }^{2,4}$ Consistent with the literature, our patient experienced resolution of bradycardia after the dose of hydrocortisone was gradually reduced to a physiological replacement dose.

Corticosteroid-induced bradycardia is not commonly detected but is a potentially serious adverse effect seen in patients who receive large or small doses of corticosteroids even for a short time and even administered using the oral route. Given the potential for hemodynamic alterations in critical illnesses, including sepsis in children with AI, it is important to be aware of the cardiovascular side effects of stress doses of hydrocortisone. Given patient-specific factors, including coexisting diseases, close observation and slow rates of infusion are recommended when administering these agents.

\section{REFERENCES}

1. Miller BS, Spencer SP, Geffner ME, Gourgari E, et al. Emergency management of adrenal insufficiency in children: advocating for treatment options in outpatient and field settings. J Investig Med. 2020; 68(1):16-25.

2. Stroeder J, Evans C, Mansell H. Corticosteroid-induced bradycardia: Case report and review of the literature. Can Pharm J (Ott). 2015; 148(5):235-40.

3. Üsküdar Cansu D, Bodakçi E, Korkmaz C. Dose-dependent bradycardia as a rare side effect of corticosteroids: a case report and review of the literature. Rheumatol Int. 2018; 38(12):2337-43.

4. Hasan AQ, Al-Khazraji A. Corticosteroids-induced bradycardia: a case report and literature review. J Med Sci Clin Res. 2016; 4(7):1566-9.

5. Vasheghani-Farahani A, Sahraian MA, Darabi L, Aghsaie $\mathrm{A}$, et al. Incidence of various cardiac arrhythmias and conduction disturbances due to high dose intravenous methylprednisolone in patients with multiple sclerosis. $J$ Neurol Sci. 2011; 309(1-2):75-8. 
6. Lucas KG, Howrie DL, Phebus CK. Cardiorespiratory decompensation following methylprednisolone administration. Pediatr Hematol Oncol. 1993; 10(3):249-255.

7. Miura M, Ohki H, Yoshiba S, Ueda H, et al. Adverse effects of methylprednisolone pulse therapy in refractory Kawasaki disease. Arch Dis Child. 2005; 90(10):1096-7.

8. Nagakura A, Morikawa Y, Sakakibara H, Miura M. Bradycardia associated with prednisolone in children with severe Kawasaki disease. J Pediatr. 2017; 185:106-11.
9. John PR, Khaladj-Ghom A, Still KL. Bradycardia Associated with Steroid Use for Laryngeal Edema in an Adult: A Case Report and Literature Review. Case Rep Cardiol. 2016; 2016:9785467.

10. Chilkoti GT, Singh A, Mohta M, Saxena AK. Perioperative "stress dose" of corticosteroid:Pharmacological and clinical perspective. J Anaesthesiol Clin Pharmacol. 2019; 35(2):14752.

11. Naranjo CA, Busto U, Sellers EM, Sandor P, et al. A method for estimating the probability of adverse drug reactions. Clin Pharmacol Ther. 1981; 30(2):239-45. 